\title{
Dynamic monitoring of circulating microRNAs as a predictive biomarker for the diagnosis and recurrence of papillary thyroid carcinoma
}

\author{
YANQING ZHANG ${ }^{1 *}$, DESHENG XU $^{2 *}$, JIAQI PAN $^{1}$, ZHENGKAI YANG $^{3}$, \\ MEIJUN CHEN ${ }^{4}$, JUN HAN $^{4}$, SIJIA ZHANG ${ }^{4}$, LULU SUN $^{4}$ and HONG QIAO ${ }^{4}$ \\ ${ }^{1}$ Department of Hematology, The Second Affiliated Hospital of Harbin Medical University, Harbin, \\ Heilongiiang 150086; ${ }^{2}$ Department of Anesthesiology, Harbin Medical University Cancer Hospital, Harbin, \\ Heilongjiang 150040; ${ }^{3}$ Department of Biochemistry, Harbin Medical University; ${ }^{4}$ Department of Endocrinology, \\ The Second Affiliated Hospital of Harbin Medical University, Harbin, Heilongjiang 150086, P.R. China
}

Received March 27, 2016; Accepted February 13, 2017

DOI: $10.3892 / 01.2017 .6028$

\begin{abstract}
Circulating microRNAs (miRNAs/miRs) are considered to be potential biomarkers for numerous types of cancer. However, previous investigations into the expression of miRNAs in the serum of patients with papillary thyroid carcinoma (PTC) to predict diagnosis, prognosis and recurrence have reported conflicting results, and the role of miRNAs remains unclear. The present study dynamically assessed the circulating miRNA profile in patients with PTC and determined whether miRNAs in the serum could be used as biomarkers for the diagnosis, prognosis and recurrence of PTC. The expression levels of 3 reportedly upregulated miRNAs (miR-222, miR-221 and miR-146b) were analyzed using reverse transcription-quantitative polymerase chain reaction in 106 patients with PTC, 35 patients with benign thyroid nodules (BTN) and 40 paired controls. Patients with either newly diagnosed PTC or BTN who were undergoing thyroidectomies were recruited for a dynamic analysis of preoperative and postoperative serum miRNA levels. The results indicated that the expression levels of serum miR-222, miR-221 and miR-146b were significantly increased in patients with newly diagnosed PTC compared with controls and patients with BTN. Receiver operating characteristic curve analysis indicated that these miRNAs had a high diagnostic sensitivity and specificity for PTC prior to surgery. The expression of these three miRNAs in serum was significantly
\end{abstract}

Correspondence to: Dr Hong Qiao, Department of Endocrinology, The Second Affiliated Hospital of Harbin Medical University, 246 Xuefu Road, Nangang, Harbin, Heilongjiang 150086, P.R. China E-mail: qiaoh0823@sina.com

\section{*Contributed equally}

Key words: papillary thyroid carcinoma, microRNA, prognosis, recurrence, circulating biomarkers associated with poorer prognostic variables, including extrathyroidal invasion, metastatic lymph nodes and high-risk or advanced tumor node metastasis stage. More notably, the present study identified 2.36-, 2.69- and 5.39-fold reductions in the serum levels of miR-222, miR-221 and miR-146b, respectively, subsequent to patients undergoing a thyroidectomy. In addition, miR-222, miR-221 and miR-146b were overexpressed in the PTC with recurrence group compared with the PTC without recurrence group. Collectively, dynamic monitoring of circulating miRNAs may serve as a non-invasive biomarker for the diagnosis of PTC and the postoperative monitoring of its progression and recurrence.

\section{Introduction}

Papillary thyroid carcinoma (PTC) is derived from the thyroid follicular epithelium. PTC is the most common type of endocrine cancer, and its rate of incidence has increased rapidly over the past several decades $(1,2)$. Currently, the vast majority of newly detected PTCs are small, localized, asymptomatic tumors that are identified incidentally (3). Therefore, the tools for diagnosing, treating and monitoring PTC are also adapting. The current challenge regarding PTC is to revise follow-up paradigms to ensure the most appropriate, cost-effective monitoring index of PTC that guarantees the best management and the quality of life for a disease that, despite an intrinsic low mortality, requires life-long follow-up care.

Thyroid ultrasound (US) is a widespread technique used as a first-line preoperative diagnostic procedure for detecting and characterizing nodular thyroid disease. US features that are associated with malignancy include hypoechogenicity, microcalcifications, an absence of a peripheral halo, irregular borders, solid aspects, intranodular blood flow and shape (taller than wide). Taken individually, each of these patterns is poorly predictive. However, when multiple patterns suggestive of malignancy are simultaneously present in a nodule, the specificity of US increases, but the sensitivity becomes unacceptably low $(4,5)$.

Fine needle aspiration cytology (FNAC) is currently the best method for the differential diagnosis of thyroid nodules $(6,7)$. 
However, FNAC has limitations associated with inadequate sampling and difficulty in discriminating follicular lesions (8). The prevalence of non-diagnostic and indeterminate FNAC remains high, at $\sim 30 \%$. The majority of these patients undergo surgery, but $<20 \%$ of surgically removed nodules are malignant $(6,9,10)$.

Various molecular markers, including BRAF, RAS, RET/PTC, paired box 8/peroxisome proliferator-activated receptor $\gamma(\operatorname{PPAR} \gamma)$ and galecton-3, have been considered for indeterminate cytology according to the American Thyroid Association guidelines (5). Although these molecular markers may aid clinicians in discriminating between PTC and BTN, the Association of Clinical Endocrinologists and the European Thyroid Association do not currently recommend these markers in routine practice. Instead, assessments using molecular markers are reserved for select cases due to their inconsistent results and relatively high costs (11).

For the majority of patients with PTC, the prognosis is excellent, with an overall 5-year survival rate of $>95 \%$. However, up to $30 \%$ of patients with PTC suffer locoregional or distant metastatic recurrence 10 years or even 20 years following initial treatment $(12,13)$. Therefore, a key issue in the management of patients with PTC is minimizing the morbidity and mortality associated with recurrent disease. Currently, there are a limited number of biomarkers are available for PTC and consist primarily of neck US or basal and recombinant human thyrotropin (rh TSH)-stimulated serum thyroglobulin (TG) measurements that may be used to identify individuals at risk of recurrence. These tests have a higher negative predictive value but a low specificity and positive predictive value (14-17). Therefore, there is a risk of subjecting numerous patients, who are likely free of disease, to extensive testing or unnecessary treatment when there is a general lack of accuracy and consensus in the diagnosis $(18,19)$. Specific and sensitive non-invasive biomarkers for the detection of PTC are required to reduce the worldwide morbidity caused by cancer and as the treatment of a disease is more effective if the underlying pathology is diagnosed early.

MicroRNAs (miRNAs/miRs) are endogenous noncoding RNA molecules that are 18-25 nucleotides in length. miRNAs have been shown to perform a key role in the regulation of gene expression. There is also evidence that miRNAs are involved in central biological processes, including development, organogenesis, tissue differentiation, cell cycles and metabolism (20,21). Alterations in the expression of miRNA contribute to the pathogenesis of the majority of human malignancies. Recently, miRNAs have also been detected in serum, plasma, urine, saliva, and other bodily fluids (22-25). Biochemical analyses have indicated that miRNAs are resistant to RNase activity and extreme $\mathrm{pH}$ and temperature. The expression patterns of circulating miRNAs, particularly serum miRNAs, are clearly correlated with various diseases, including cancer, and may have potential for use as novel minimally invasive biomarkers for diagnosing and monitoring human cancer.

miRNA expression is altered in thyroid tumors, suggesting a role for miRNA in thyroid carcinogenesis (26-28). Previous studies on miRNA deregulation have demonstrated increased aberrant miRNA expression (particularly miR-222, miR-221 and miR-146b) in PTCs when compared with normal thyroid tissues and BTN (29-32). These data indicate that miRNAs may be useful diagnostic and prognostic markers for PTC and may even function as therapeutic targets. However, the majority of these reports regarding miRNA expression are based on findings from tumor tissue specimens. Although tissue miRNA profiles may be useful for distinguishing benign from malignant lesions, obtaining the tumor tissue is not a suitable presurgical diagnosis. To date, a limited number of reports have addressed the possibility of evaluating circulating miR-222, miR-221 and miR-146b levels in patients with PTC, and their conclusions remain controversial (29,33-35).

These considerations provided the basis for the present study, which developed a novel screening approach that specifically detects the diagnosis and recurrence of PTC. The present study validated the expression of serum miR-222, miR-221 and miR-146b, which have previously been reported as miRNAs in tumor tissues and cell lines that are able to differentiate PTCs from BTN and controls. The present study focused on the dynamic monitoring of miRNA profiles prior to and subsequent to surgery to elucidate whether the abnormal expression of specific miRNAs is associated with the diagnosis, prognosis and recurrence of PTC and whether there are associated clinicopathological factors in patients with PTC.

\section{Materials and methods}

Patients. A total of 106 PTC patient, of which 85 were newly clinically diagnosed with PTC and 21 cases of PTC with newly suspicious neck masses or lymph nodes subsequent to an initial curative treatment. In addition 35 patients with BTN who had single or multiple nodules and were undergoing a thyroidectomy. These patients were enrolled from the Department of Thyroid Surgery of the Second Affiliated Hospital of Harbin University (Heilongjiang, China) between September 2013 and December 2015. In total, 40 control subjects were enrolled from the Physical Examination Center of the Second Affiliated Hospital of Harbin University (Heilongjiang, China) between September 2013 and December 2015. The surgical procedure for patients with PTC was performed according to the revised American Thyroid Association management guidelines for pathway with thyroid nodules and differentiated thyroid cancer (5). A more detailed explanation of the procedures is provided below. For patients with thyroid cancer tumors $>1 \mathrm{~cm}$, the initial surgical procedure must be a near-total or total thyroidectomy. If surgery is selected for patients with PTC with a tumor $<1 \mathrm{~cm}$ without extrathyroidal extension, the unifocal surgical procedure must be a hemithyroidectomy (5). For patients with BTN, the surgical procedure must be a hemithyroidectomy. The 40 control subjects were age- and gender-matched volunteers without a current or previous history of any other types of cancer and were confirmed to not have thyroid disease based on a neck US and thyroid hormone measurements. The characteristics of the patients with PTC in this study are presented in Table I. The clinical stage was classified according to the American Joint Committee on Cancer (2010, 7th edition) tumor node metastasis (TNM) classification system (36). Patients were stratified into low- and high-risk PTCs according to the age, metastasis, extension and size risk-group classification (37). All pathological results for these patients were verified by the Department of Pathology at 


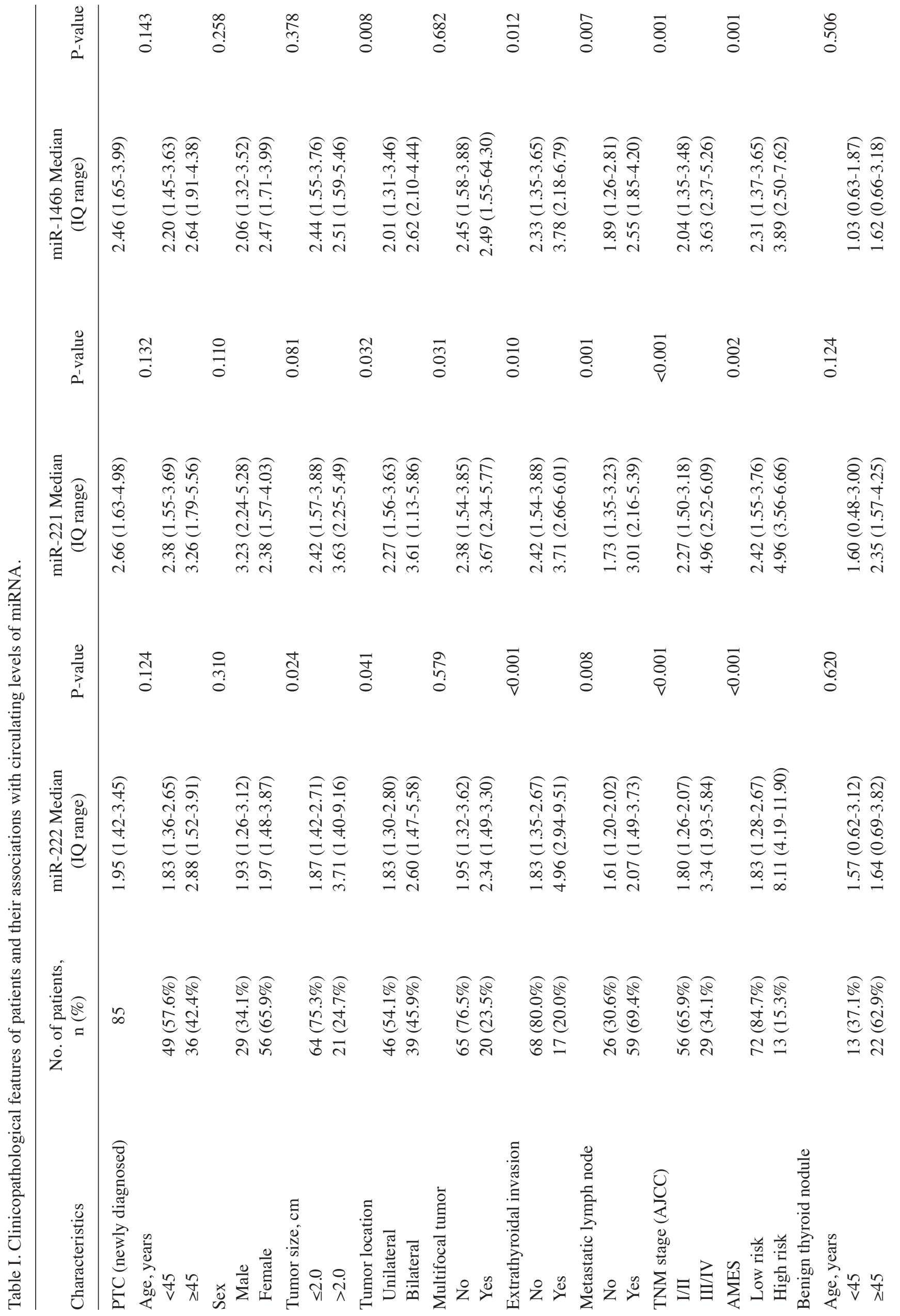




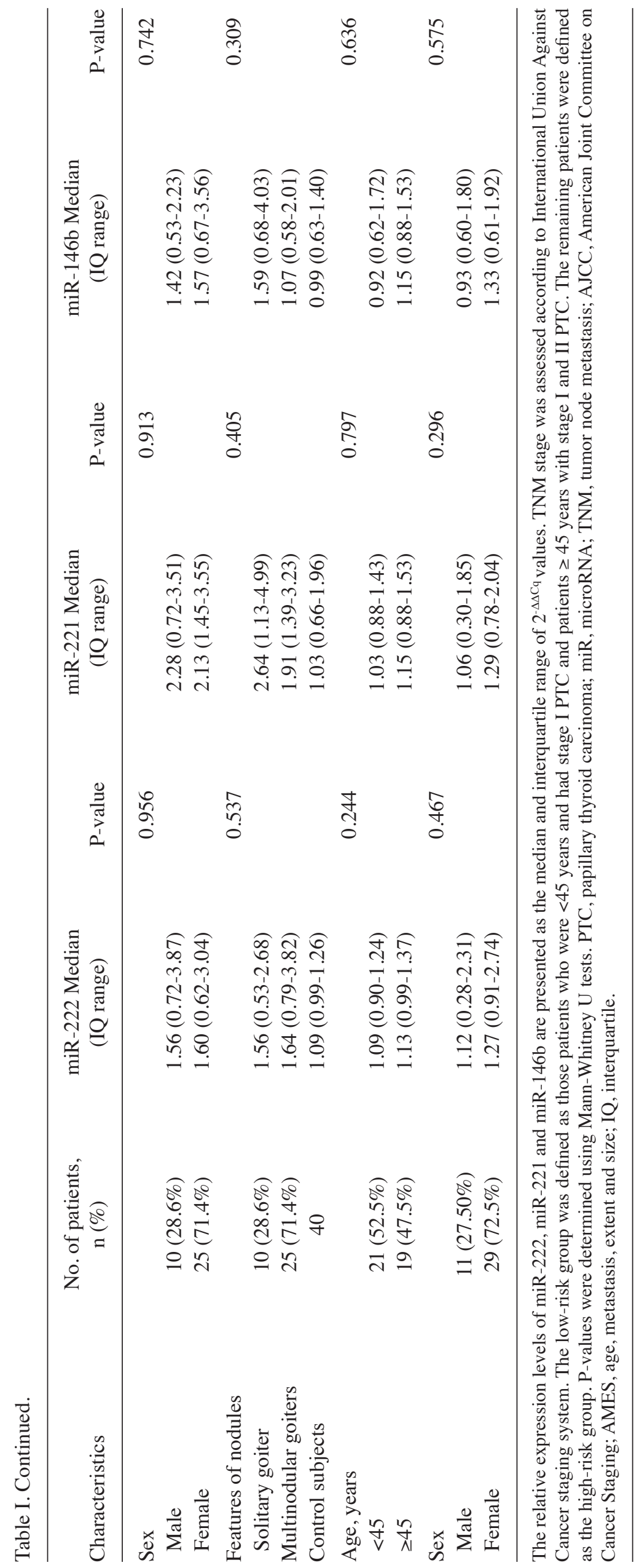


Table II. miRNA-specific forward primer sequences.

Gene name $\quad$ Primer sequence (5'-3')

miR-222

miR-221

miR-146b

miR-16

GGGCTCAGTAGCCAGTGTAGATCC GGCGACCTGGCATACAATGTAGAT GGCTGAGAACTGAATTCCATAGGC GCTAGCAGCACGTAAATATTGGCG

miR, microRNA.

the Second Affiliated Hospital of Harbin Medical University. Tumor recurrence was defined as new evidence of a pathologically proven recurrence in a patient who initially met the criteria for remission. The criteria for remission was no clinical or imaging evidence of tumors.

The present study was approved by the Institutional Review Board of Harbin Medical University. Written informed consent was obtained from all participants involved in the present study.

Serum samples and RNA extraction. Fasting peripheral blood samples were collected in vacuum-sealed blood collection tubes from all control subjects and patients with PTC and BTN on the day of surgery. Samples from prior to and subsequent to surgery were separated into serum and cellular components within $1 \mathrm{~h}$ of collection by centrifugation at $1,900 \mathrm{x} \mathrm{g}$ for $15 \mathrm{~min}$ at $4^{\circ} \mathrm{C}$. The supernatant was carefully transferred into an RNase-free tube and centrifuged at 12,000 x g for $10 \mathrm{~min}$ at $4^{\circ} \mathrm{C}$ to remove additional cellular debris and to minimize the contamination of cell-free nucleic acid by DNA and RNA derived from damaged blood cells. The serum samples were stored at $-80^{\circ} \mathrm{C}$ until RNA extraction.

Total RNA was isolated from $200 \mu \mathrm{l}$ of serum according to the manufacturer's protocol using a miRNeasy serum/plasma kit (Qiagen GmbH, Hilden, Germany). Briefly, 1,000 $\mu$ l of QIAzol lysis reagent and $3.5 \mu l$ of the miRNeasy serum/plasma spike-in control (C. elegans miR-39 miRNA mimic, $1.6 \times 10^{8}$ copies $/ \mu 1$ working solution) were added to $200 \mu \mathrm{l}$ of serum and incubated at room temperature for $5 \mathrm{~min}$. The C. elegans miR-39 miRNA mimic was used as an external reference to validate whether miR-16 may be utilized as an endogenous reference. An equal volume of chloroform was added to the starting sample, and the samples were centrifuged for $15 \mathrm{~min}$ at $12,000 \mathrm{x} \mathrm{g}$ at $4^{\circ} \mathrm{C}$ until there was complete phase separation.

The upper aqueous phase was quickly transferred to a new collection tube, and 1.5 volumes of $100 \%$ ethanol were added to the sample, which was mixed thoroughly. The sample was transferred into an RNeasy MinElute spin column (Qiagen GmbH, Hilden, Germany) in a $2 \mathrm{ml}$ collection tube and centrifuged at $8,000 \mathrm{x}$ g for $15 \mathrm{sec}$ at room temperature and the flow-through was discarded. The RNeasy MinElute spin columns were washed with $700 \mu \mathrm{l}$ of buffer RWT, $500 \mu \mathrm{l}$ of buffer RPE and $80 \%$ ethanol. The precipitated RNA was resuspended in $14 \mu \mathrm{l}$ of RNase-free water. The final elution volume was $12 \mu \mathrm{l}$. The concentrations of all RNA samples were quantified using a NanoDrop 1000 spectrophotometer (NanoDrop Technologies; Thermo Fisher Scientific, Inc.,
Wilmington, DE, USA). The concentrations of RNA extracted from plasma ranged between 15.9 and $24.7 \mathrm{ng} / \mathrm{ml}$.

Selection and detection of miRNAs. The miRNA candidates to be tested were selected based on the following process. Firstly, miRNAs that were enriched in normal thyroid tissues and significantly unregulated in PTC compared with normal thyroid tissues and BTN were selected $(29-31,38)$. Published reports describing the analysis of circulating miRNAs in plasma or serum were then examined $(29,33)$. This step was critical since miRNA expression levels in various tissues do not generally correlate with their concentrations in plasma or serum in patients with PTC $(29,33,34)$, and the serum or plasma levels of tissue-enriched miRNAs can be significantly lower compared with levels of ubiquitous miRNAs. Finally, miRNAs that were significantly associated with a poor prognosis of PTC were selected $(29,30,33,34,38,39)$. Based on this selection procedure, 3 miRNAs (miR-222, miR-221 and miR-146b) were selected as candidate targets for the serum miRNA assay.

Reverse transcription-quantitative polymerase chain reaction $(R T-q P C R)$. First-strand cDNA synthesis of miRNA was performed using a miRcute miRNA first-strand cDNA synthesis kit (Tiangen Biotech Co. Ltd., Beijing, China) according to the manufacturer's protocol. Reverse transcription was conducted on a GeneAmp PCR System 9700 (Applied Biosystems; Thermo Fisher Scientific, Inc., Waltham, MA, USA). Briefly, $5 \mu \mathrm{l}$ of total RNA was extracted from plasma, polyadenylated by poly (A)polymerase and reverse transcribed to cDNA according to the manufacturer's protocol. The cycle parameter for the reverse transcription reaction was $37^{\circ} \mathrm{C}$ for $60 \mathrm{~min}$. cDNA was stored at $20^{\circ} \mathrm{C}$ prior to use.

RT-qPCR was performed in duplicate using the SYBR Green PCR master mix (miRcute miRNA qPCR detection kit; Tiangen Biotech Co., Ltd.) with the Stratagene Mx3000PTM real-time PCR system (Applied Biosystems; Thermo Fisher Scientific, Inc.). miRNA-specific primer sequences were designed based on the miRBase database by Primer Premier 5.0 and are presented in Table II. Each reaction was performed in a final volume of $20 \mu \mathrm{l}$ containing $2 \mu \mathrm{l}$ of the cDNA, $0.4 \mu \mathrm{l}$ of each primer and $10 \mu \mathrm{l}$ of SYBR Green PCR Master mix (Tiangen Biotech Co., Ltd.). The amplification cycle was denaturation at $94^{\circ} \mathrm{C}$ for $2 \mathrm{~min}$ followed by 45 cycles at $94^{\circ} \mathrm{C}$ for $20 \mathrm{sec}$ and $60^{\circ} \mathrm{C}$ for $34 \mathrm{sec}$. All real-time PCR reactions were performed in triplicate.

miR-16 has been used as an endogenous reference for serum and plasma miRNA analysis in several studies (40-44). It is highly expressed in plasma and serum and is relatively invariant across large numbers of samples, as reported by Kroh et al (40). Therefore, the present study utilized miR-16 as the endogenous serum control. $\Delta \mathrm{Cq}$ was calculated by subtracting the $\mathrm{Cq}$ value of miR-16 from the $\mathrm{Cq}$ value of the miRNA of interest. $\Delta \Delta \mathrm{Cq}$ was then calculated by subtracting $\Delta \mathrm{Cq}$ of the control group from $\Delta \mathrm{Cq}$ of the disease group. The fold-change in the expression of each miRNA was determined by comparing the mean $2^{-\Delta \Delta \mathrm{Cq}}$ values of the PTC and BTN groups to the mean $2^{-\Delta \Delta \mathrm{Cq}}$ value of the control group (45).

Statistical analysis. Statistical analysis was performed using SPSS version 17.0 (SPSS, Inc., Chicago, IL, USA). The 


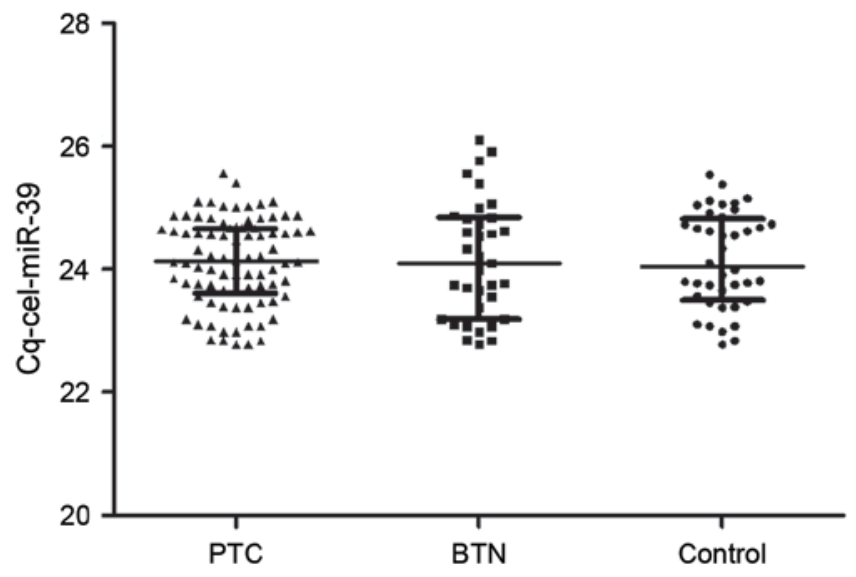

Figure 1. Cq values for spiked miR-39 from Caenorhabditis elegans (cel-miR-39) mimic in the serum of the PTC, BTN and control groups ( $\mathrm{n}=85,35$ and 40 , respectively). Statistical analysis was performed using the Mann-Whitney U test. No significant difference was observed between these 3 groups. miR, microRNA; PTC, papillary thyroid carcinoma; BTN, benign thyroid nodules; $\mathrm{Cq}$, quantification cycle.

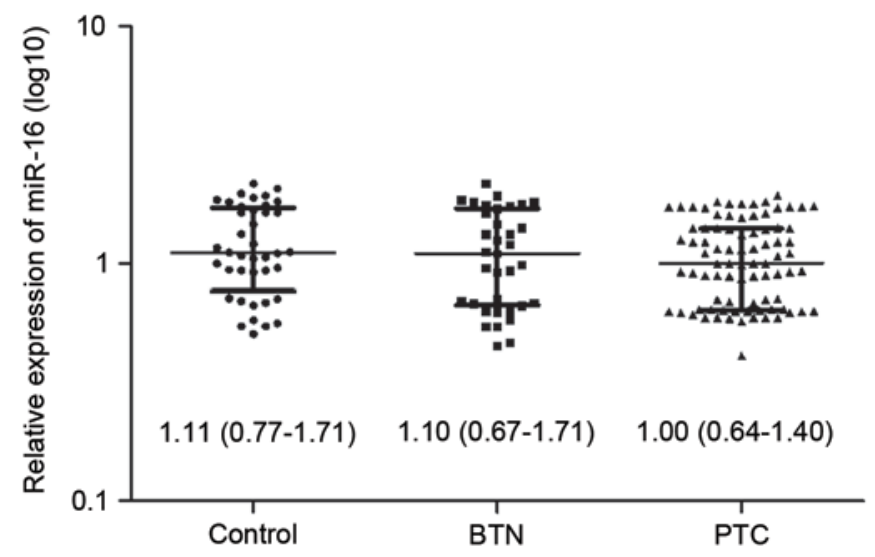

Figure 2. Scatter plot of miR-16 levels in serum from patients in the PTC, BTN and control groups ( $\mathrm{n}=85,35$ and 40 , respectively). miR-16 levels did not differ significantly between the PTC group and the BTN or control groups ( $\mathrm{P}>0.05$ for all comparisons). The lines inside the scatter plot denote the median with the interquartile range. All indicated P-values were determined using the Mann-Whitney U test. miR, microRNA; PTC, papillary thyroid carcinoma; BTN, benign thyroid nodules.

Mann-Whitney U test was used to determine the significance of the different levels of miRNA expression. Fisher's exact test was used to measure the characteristics in the PTC with recurrence (PTC-RC) and PTC without recurrence (PTC-NR) groups. Receiver operating characteristic (ROC) curves were used to analyze the diagnostic utility of differentially expressed miRNAs. The optimal cutoff point was selected as the value with the maximal sum of sensitivity and specificity. The levels of miRNA in each group were defined by the median and interquartile range (IQR). All P-values were two-sided. $\mathrm{P}<0.05$ was considered to indicate a statistically significant difference.

\section{Results}

Analysis of circulating miR-16 in serum. Initially, the presence of circulating miR-16 in serum was analyzed. Cel-miR-39 expression levels in serum from patients with
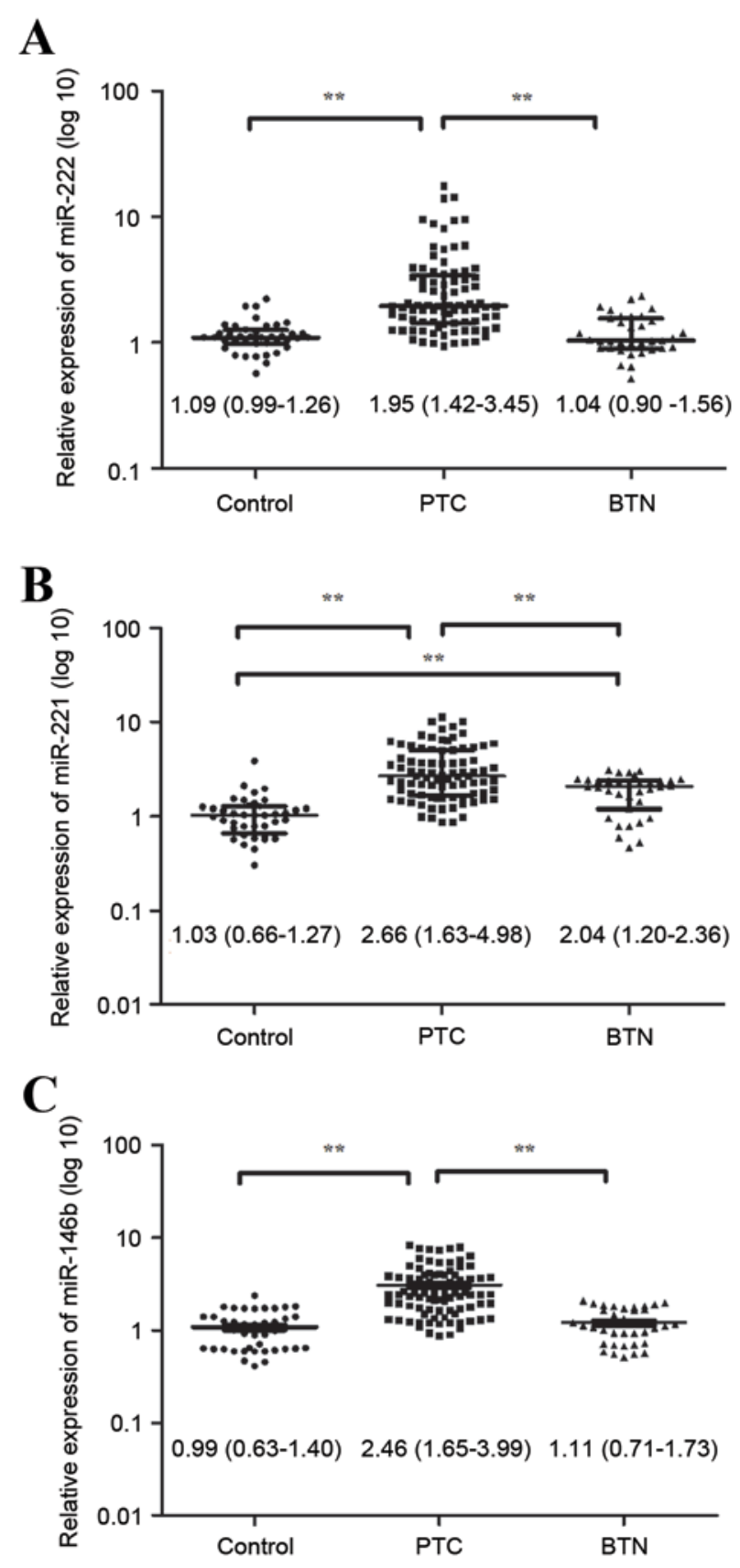

Figure 3. Diagram of Mann-Whitney U test results, demonstrating that the relative expression levels of (A) miR-222, (B) miR-221 and (C) miR-146b in the PTC group $(n=85$; median $=1.95,2.66$ and 2.46 ; interquartile range $=1.42-3.45,1.63-4.98$ and $1.65-3.99$, respectively) were significantly increased compared with in the control $(\mathrm{n}=40$; median $=1.09,1.03$ and 0.99 ; interquartile range $=0.99-1.26,0.66-1.27$ and $0.63-1.40$, respectively) and BTN $(\mathrm{n}=35$; median $=1.04,2.04$ and 1.11 ; interquartile range $=0.90-1.56,1.20-2.36$ and 0.71-1.73, respectively) groups. For miR-222 and miR-146b, there was no significant difference in expression between the BTN and control groups $(\mathrm{P}=0.983$ and $\mathrm{P}=0.232)$. For miR-221, there was a significant difference in expression levels between the BTN and control groups $\left({ }^{* *} \mathrm{P}<0.01\right)$. Relative miRNA expression is presented as the log 10 of target miRNA expression values. miR; microRNA; PTC, papillary thyroid carcinoma; BTN, benign thyroid nodules.

PTC were similar to those observed in the BTN and control groups. There was no significant difference among these 3 groups $(\mathrm{P}=0.808, \mathrm{P}=0.828$ and $\mathrm{P}=0.959$, respectively; Fig. 1$)$. To confirm that the present results were not due to technical biases, miR-16 was normalized with spiked cel-miR-39 and no 
A

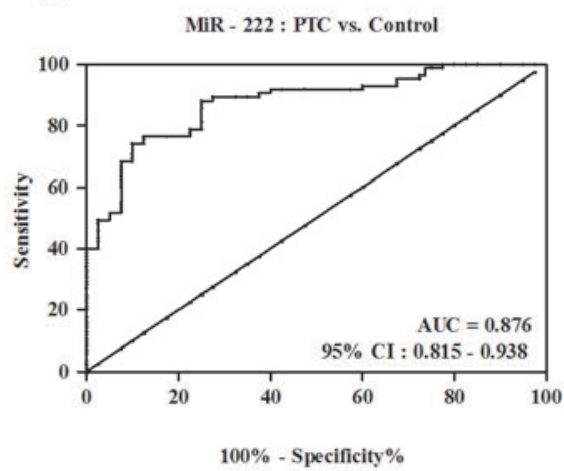

C

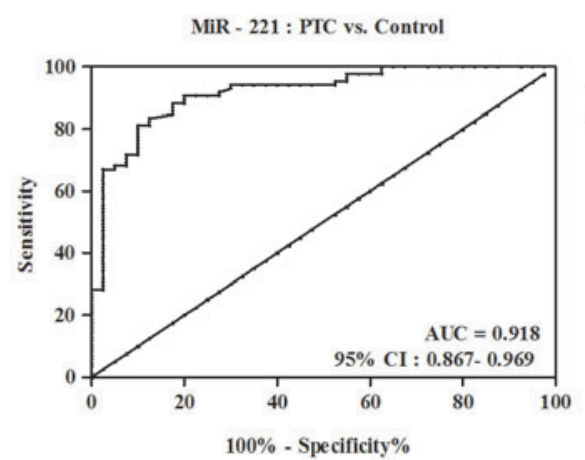

E

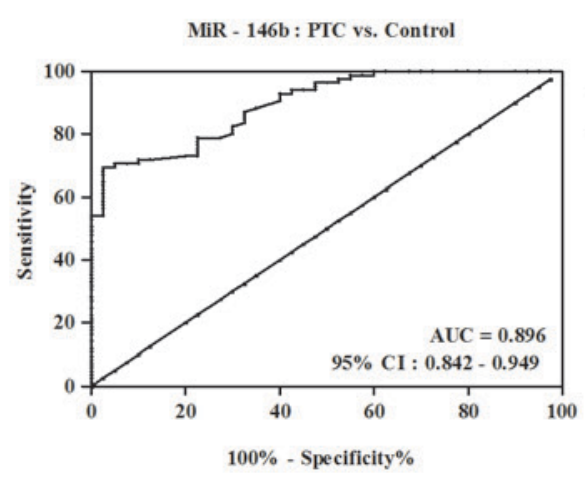

G

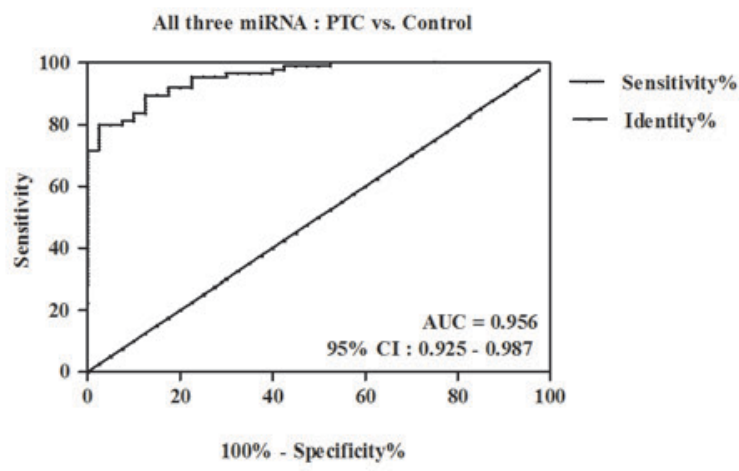

B

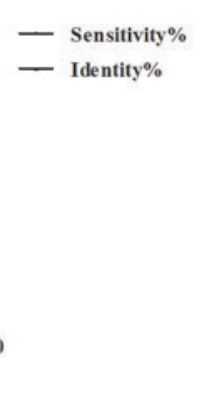

- Sensitivity\%

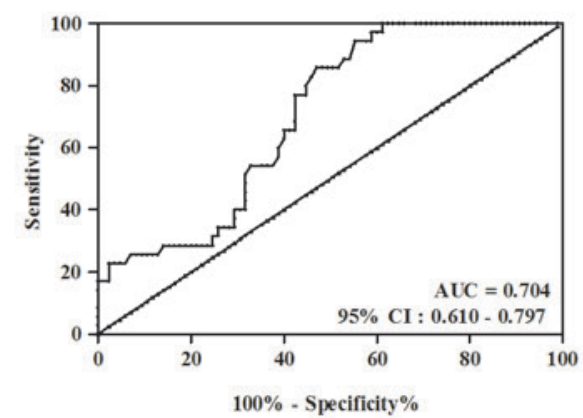

- Sensitivity $\%$

- Identity $\%$
F

MiR - 146b : PTC vs. BTN

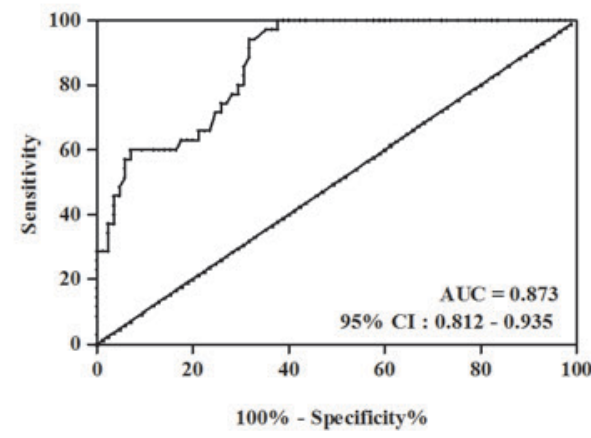

H

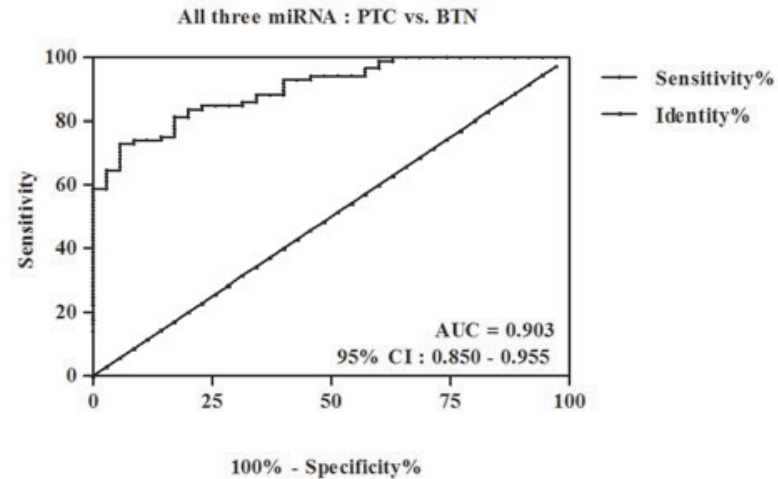

Figure 4. Diagnostic value of miRNAs in discriminating PTC from controls and BTN. ROC curves were used to distinguish among groups. (A) Serum miR-222 in PTC vs. controls and (B) BTN. (C) Serum miR-221 in PTC vs. controls and (D) BTN. (E) Serum miR-146b in PTC vs. control and (F) BTN. (G) All three miRNA (miR-222, miR-221 and miR-146b) in PTC vs. controls and (H) BTN. miR, microRNA; PTC, papillary thyroid carcinoma; BTN, benign thyroid nodules; ROC, receiver operating characteristic; AUC, area under the curve. 
A

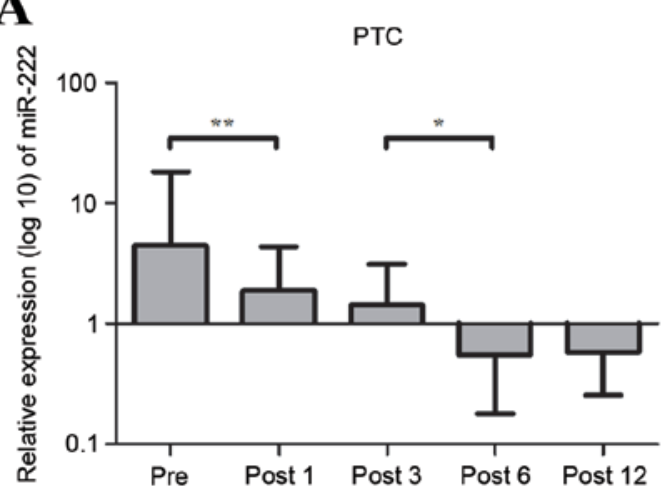

C

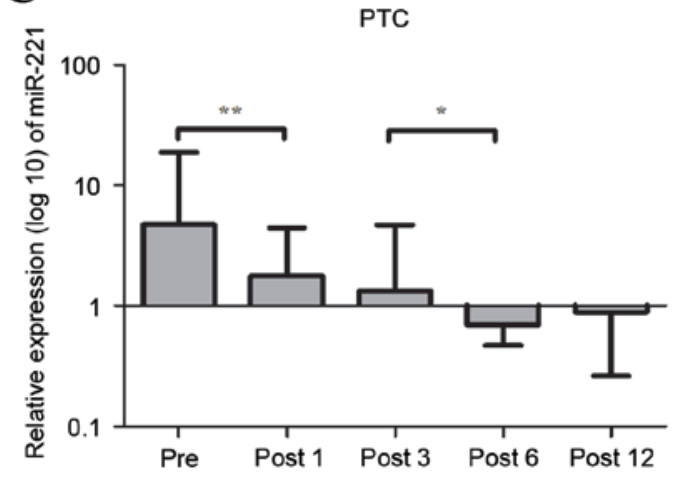

$\mathbf{E}$

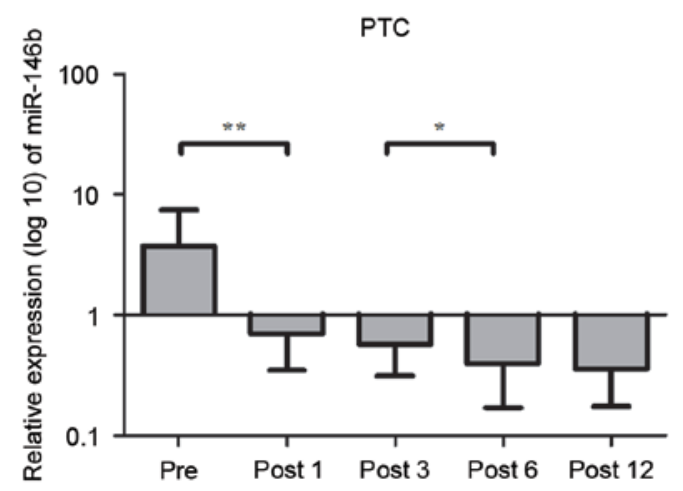

B

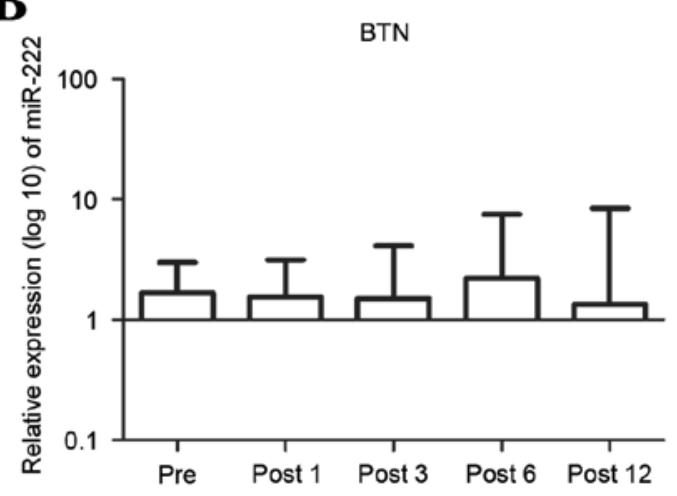

D

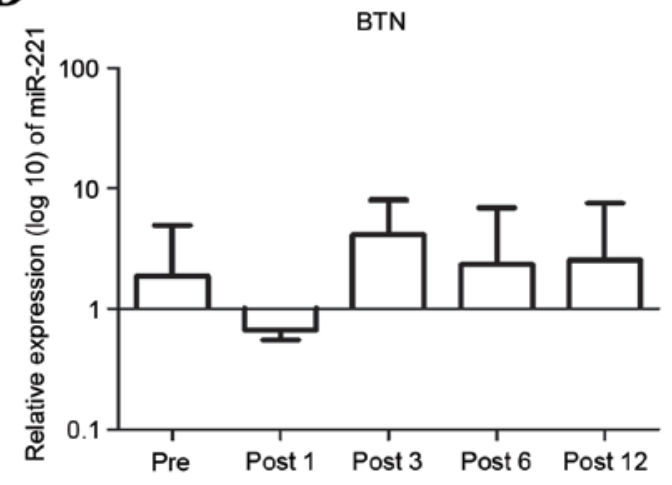

$\mathbf{F}$

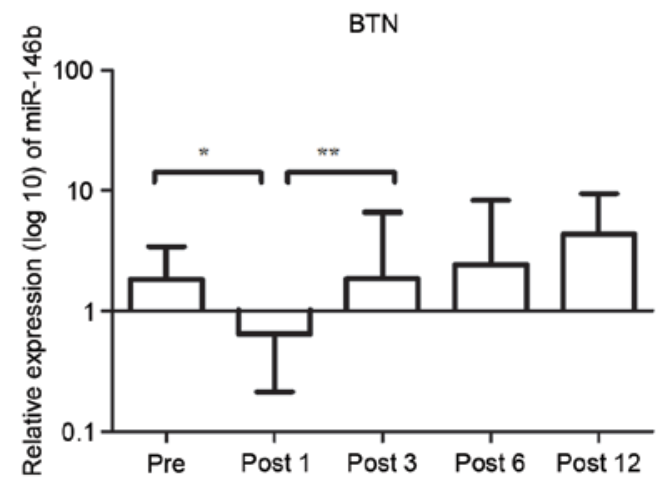

Figure 5. The expression levels of miR-222, miR-221 and miR-146b in patients with PTC $(n=28)$ and BTN $(n=16)$ preoperatively, and at 1,3,6 and 12 months postoperatively. miR-222 expression levels in (A) PTC and in (B) BTN. miR-221 expression levels in (C) PTC and in (D) BTN. miR-146b expression levels in (E) PTC and in (F) BTN. miR-222, miR-221 and miR-146b decreased significantly 1 month following surgery compared with the preoperative level in patients with PTC ( $\left.{ }^{* *} \mathrm{P}<0.01\right)$. miR-222, miR-221 and miR-146b gradually decreased between 3 and 6 months following surgery in the PTC group ( $\left.\mathrm{P}<0.05\right)$. miR-146b decreased significantly 1 month following surgery compared with the preoperative level $(" \mathrm{P}<0.05)$ and increased significantly at 1 month compared with 3 months following surgery in the BTN group $\left({ }^{* *} \mathrm{P}<0.01\right)$. Relative expression is presented as $2^{-\Delta \Delta C q}$ values. All P-values were determined using the Mann-Whitney U test. miR, microRNA; PTC, papillary thyroid carcinoma; BTN, benign thyroid nodules; pre, preoperative; post, postoperative.

significant differences were revealed in miR-16 values among PTC patients, BTN patients and controls $(\mathrm{P}=0.135, \mathrm{P}=0.432$ and $\mathrm{P}=0.630$; respectively; Fig. 2). These results indicate that miR-16 is an appropriate endogenous normalizer.

Serum miRNA expression patterns in patients with PTC or BTN and control subjects. The present study used RT-qPCR to measure the expression levels of serum miR-222, miR-221 and miR-146b from all enrolled subjects. No significant differences were identified in terms of age or sex among the 3 groups $(\mathrm{P}=0.288$ and $\mathrm{P}=0.940$, respectively). The serum levels of miR-222, miR-221 and miR-146b were significantly higher in patients with newly diagnosed PTC compared with those with BTN or in the control subjects $(\mathrm{P}<0.001$ and $\mathrm{P}<0.001$, 

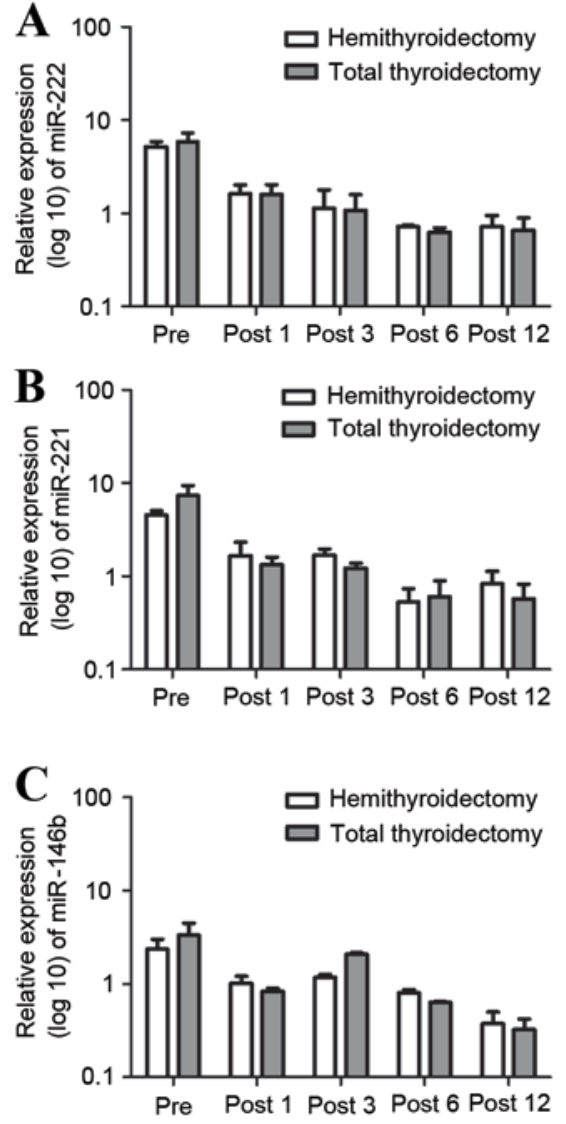

Figure 6. The relative expression levels of (A) miR-222, (B) miR-221 and (C) miR-146b in patients with PTC with a hemithyroidectomy $(n=10)$ and a total thyroidectomy $(\mathrm{n}=18)$ groups at preoperative levels, and 1, 3,6 and 12 months postoperatively. The three miRNA levels were not significantly different in the hemithyroidectomy group relative to the total thyroidectomy group prior to and subsequent to surgery ( $\mathrm{P}>0.05$ for all comparisons). miR, microRNA; PTC, papillary thyroid carcinoma; pre, preoperative; post, postoperative.

respectively; Fig. 3). The fold-changes were 1.79, 2.58 and 2.48 , respectively, compared with the controls. In addition, miR-221 was overexpressed in patients with BTN compared with control subjects $(\mathrm{P}<0.001)$, with a fold-change of 1.98 . However, no significant difference was identified in the serum levels of miR-222 and miR-146b between patients with BTN and control patients $(\mathrm{P}=0.983$ and $\mathrm{P}=0.232$, respectively).

An ROC curve analysis was used to evaluate the diagnostic value of serum miR-222, miR-221 and miR-146b levels for PTC. A comparison of the PTC and control groups indicated that using all 3 miRNAs produces an area under the curve (AUC) of 0.956 [95\% confidence interval (CI), 0.925-0.987] with $72.94 \%$ sensitivity and $94.29 \%$ specificity at the cutoff value of 0.73 . Individually, miR-222 had an AUC of 0.876 (95\% CI, 0.815-0.938), miR-221 had an AUC of 0.918 (95\% CI, 0.867-0.969) and miR-146b had an AUC of 0.896 (95\% CI, 0.842-0.949). At cutoff values of 1.46, 1.49 and 1.83 for miR-222, miR-221 and miR-146b, respectively, the sensitivity and specificity values were 74.12 and $90 \%, 83.53$ and $87.50 \%$, and 69.41 and $97.50 \%$, respectively.

A comparison of the PTC and BTN groups indicated that the use of all 3 miRNAs had an AUC of 0.903 (95\% CI, $0.850-0.955$ ) with $80 \%$ sensitivity and $97.50 \%$ specificity at the cutoff value of 0.70. Individually, miR-222 had an AUC of
0.840 (95\% CI, 0.766-0.914), miR-221 had an AUC of 0.704 (95\% CI, 0.610-0.797) and miR-146b had an AUC of 0.873 (95\% CI, 0.812-0.935). At cutoff values of 1.21, 2.51 and 1.94 for miR-222, miR221 and miR-146b, respectively, the sensitivity and specificity values were 62.86 and $88.24 \%, 85.71$ and $52.94 \%$ and 94.29 and $68.24 \%$, respectively (Fig. 4).

Correlation of miRNA levels and clinicopathological characteristics of PTC. As the levels of miR-222, miR-221 and miR-146b were significantly elevated in newly diagnosed patients with PTC, the present study also assessed whether any of the clinicopathological features of PTCs were associated with differential expression levels of the 3 miRNAs. The results indicated that serum miR-222, miR-221 and miR-146b levels were significantly higher in patients with extrathyroid invasion $(\mathrm{P}<0.001, \mathrm{P}=0.010$ and $\mathrm{P}=0.012$, respectively); patients with advanced TNM stage (III/IV; $\mathrm{P}<0.001, \mathrm{P}<0.001$ and $\mathrm{P}=0.001$, respectively); high-risk patients $(\mathrm{P}<0.001$, $\mathrm{P}=0.002$ and $\mathrm{P}=0.001$, respectively); patients with metastatic lymph nodes $(\mathrm{P}=0.008, \mathrm{P}=0.001$ and $\mathrm{P}=0.007$, respectively); patients with bilateral tumors $(\mathrm{P}=0.041, \mathrm{P}=0.032$ and $\mathrm{P}=0.008$, respectively). The present results also indicate that serum miR-222 overexpression is clearly associated with tumor size $(>2 \mathrm{~cm}, \mathrm{P}=0.024)$ and that serum miR-221 overexpression is associated with multifocal lesions $(\mathrm{P}=0.031)$. The levels of these 3 miRNAs were not correlated with age or gender in any group ( $\mathrm{P}>0.05$, Table I). In addition, no significant differences were found between patients with solitary or multifocal BTN $(\mathrm{P}=0.537, \mathrm{P}=0.405$ and $\mathrm{P}=0.309$, respectively).

Dynamic monitoring of miRNAs in the serum of PTC and $B T N$ patients prior to and subsequent to surgery. To additionally investigate whether levels of specific circulating miRNAs may be used to monitor postoperative progression, miR-222, miR-221 and miR-146b were evaluated via subsequent RT-qPCR during varied postoperative periods in the same patients (Fig. 5). The time points included a preoperative sample and samples at 1, 3,6 and 12 months postoperatively in the PTC and BTN groups, including 28 patients with PTC and 16 patients with BTN. miR-222, miR-221 and miR-146b rapidly decreased 1 month following surgery compared with their preoperative levels $(\mathrm{P}<0.001, \mathrm{P}<0.001$ and $\mathrm{P}<0.001$, respectively) in the PTC group. The fold-changes of miR-222, miR-221 and miR-146b were 2.36,2.69 and 5.39, respectively, in the PTC group prior to surgery compared with 1 month subsequent to surgery. In addition, the levels of miR-222, miR-221 and miR-146b decreased between 1 and 12 months following surgery in the PTC group. miR-222, miR-221 and miR-146b levels also decreased gradually and had significant differences at 3 months compared with 6 months following surgery in the PTC group ( $\mathrm{P}<0.001, \mathrm{P}=0.003$ and $\mathrm{P}=0.022$, respectively). A similar pattern was observed for miR-146b expression in the BTN group, with rapidly decreased expression following surgery $(\mathrm{P}=0.010)$. The fold-change of miR-146b was 2.88 in the BTN group prior to surgery compared with 1 month subsequent to surgery. No change was identified between the miR-222 and miR-221 expression levels prior to surgery and $1,3,6$ and 12 months following surgery in the BTN group ( $P>0.05$ ). However, miR-146b increased at 1 month following surgery compared with 3 months following surgery $(\mathrm{P}=0.001)$. 
Table III. Characteristics of patients with recurrence and with no recurrence.

\begin{tabular}{|c|c|c|c|}
\hline Characteristics & PTC-RC, $n=12$ & PTC-NR, n=9 & P-value \\
\hline \multicolumn{4}{|l|}{ Sex, n $(\%)$} \\
\hline Male & $5(41.7)$ & $3(33.3)$ & \multirow[t]{2}{*}{1.00} \\
\hline Female & $7(58.3)$ & $6(66.7)$ & \\
\hline Age, year (mean \pm SD) & $49.73 \pm 15.60$ & $47.75 \pm 10.81$ & 0.76 \\
\hline \multicolumn{4}{|l|}{ Tumor size, cm (\%) } \\
\hline$\leq 2.0$ & $4(33.3)$ & $5(55.6)$ & \multirow[t]{2}{*}{0.39} \\
\hline$>2.0$ & $8(66.7)$ & $4(44.4)$ & \\
\hline \multicolumn{4}{|l|}{ Tumor location, n (\%) } \\
\hline Unilateral & $3(25.0)$ & $3(33.3)$ & \multirow[t]{2}{*}{1.00} \\
\hline Bilateral & $9(75.0)$ & $6(66.7)$ & \\
\hline \multicolumn{4}{|l|}{ Multicentricity, n (\%) } \\
\hline Yes & $6(50.0)$ & $5(55.6)$ & \multirow[t]{2}{*}{1.00} \\
\hline No & $6(50.0)$ & $4(44.4)$ & \\
\hline \multicolumn{4}{|l|}{ Extrathyroidal invasion, $\mathrm{n}(\%)$} \\
\hline Yes & $5(41.7)$ & $2(22.2)$ & \multirow[t]{2}{*}{0.64} \\
\hline No & $7(58.3)$ & $7(77.8)$ & \\
\hline \multicolumn{4}{|l|}{ Metastatic lymph node, n (\%) } \\
\hline Yes & $11(91.7)$ & $7(77.8)$ & \multirow[t]{2}{*}{0.55} \\
\hline No & $1(8.3)$ & $2(22.2)$ & \\
\hline \multicolumn{4}{|l|}{ TNM stage, $\mathrm{n}(\%)$} \\
\hline $\mathrm{I} / \mathrm{II}$ & $5(41.7)$ & $4(44.4)$ & \multirow[t]{2}{*}{1.00} \\
\hline III/IV & $7(58.3)$ & $5(55.6)$ & \\
\hline \multicolumn{4}{|l|}{ AMES, n $(\%)$} \\
\hline Low risk & $9(75.0)$ & $8(88.9)$ & \multirow[t]{2}{*}{0.60} \\
\hline High risk & $3(25.0)$ & $1(11.1)$ & \\
\hline DFS, median month (range) & $52(10-124)$ & $51.5(16-108)$ & 0.90 \\
\hline miR-222, RQ: Median (IQR) & $7.53(3.38-9.53)$ & $1.49(1.06-1.53)$ & $<0.001$ \\
\hline miR-221, RQ: Median (IQR) & $4.63(3.58-7.52)$ & $1.53(1.40-1.68)$ & $<0.001$ \\
\hline miR-146b, RQ: Median (IQR) & $4.60(3.66-13.14)$ & $2.25(1.88-3.02)$ & 0.001 \\
\hline
\end{tabular}

Relative expression of miR-222, miR-221 and miR-146b is presented as the median and interquartile range. P-values were calculated using Fisher's exact test. Serum levels of miR-222, miR-221 and miR-146b were significantly higher in PTC-RC compared with in PTC-NR $(\mathrm{P}<0.001)$. P-values were determined using the Mann-Whitney U test. PTC-RC, papillary thyroid carcinoma with recurrence; PTC-NR, papillary thyroid carcinoma without recurrence; SD, standard deviation; TNM, tumor node metastasis; AMES, age, metastasis, extent and size; DFS, disease-free survival; miR, microRNA; RQ, relative expression; IQR, interquartile range.

There was also no observed difference in the miR-222, miR-221 and miR-146b expression levels for patients with PTC undergoing hemithyroidectomy or total thyroidectomy prior to and subsequent to surgery ( $\mathrm{P}>0.05$, Fig. 6).

Differentially expressed miRNAs in the serum of PTC with and without recurrence following initial surgery. In the present study, 21 patients with a history of thyroidectomy due to PTC were recruited as they had newly emerged lymph nodules or invasions in other locations that were suspicious of recurrence and were detected by cervical ultrasonography and medical examinations (Table III). A total of 12 patients were confirmed to have recurrence, and the remaining 9 patients were diagnosed with no recurrence by histology following a second surgical procedure. Of the 12 patients with recurrence, 7 developed a recurrence in the central neck lymph nodes, 4 in the lateral neck lymph nodes and 1 in the perithyroid soft tissues and lateral neck lymph nodes. The median time of recurrence was 52 months (range, 10-124 months). It was demonstrated that miR-222, miR-221 and miR-146b levels were significantly elevated in the PTC-RC group of patients compared with the PTC-NR group of patients $(\mathrm{P}<0.001)$ and controls $(\mathrm{P}<0.001)$. The relative expression levels of miR-222, miR-221 and miR-146b in the PTC-RC group $(\mathrm{n}=12$; median=7.53, 4.63 and 4.60; range=3.38-9.53, 3.58-7.52 and 3.66-13.14, respectively; Fig. 7) were significantly increased compared with the control $(n=20$; median=1.09, 1.14 and 1.23 ; range $=0.80-1.20,0.81-1.49$ and $0.70-1.71$, respectively; Fig. 7) and PTC-NR groups $(n=9 ;$ median=1.16, 1.53 and 2.25; range=0.96-1.53, 1.40-1.68 and 1.88-3.02, respectively; Fig. 7). In addition, miR-221 and miR-146b levels were significantly 


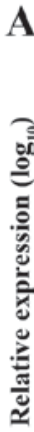

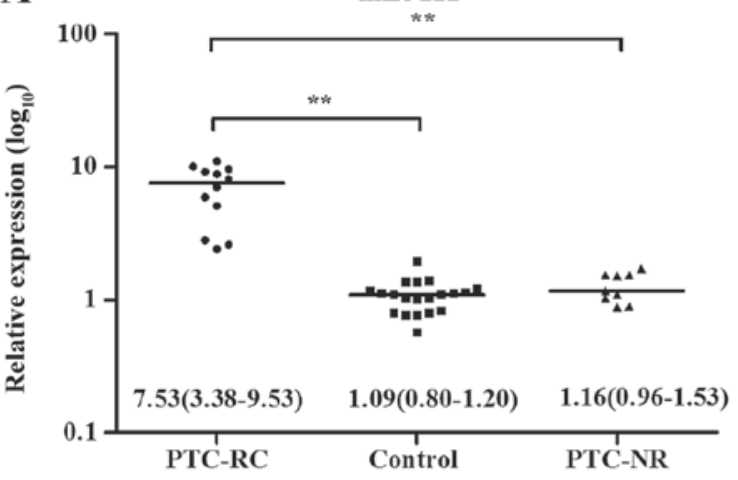

B

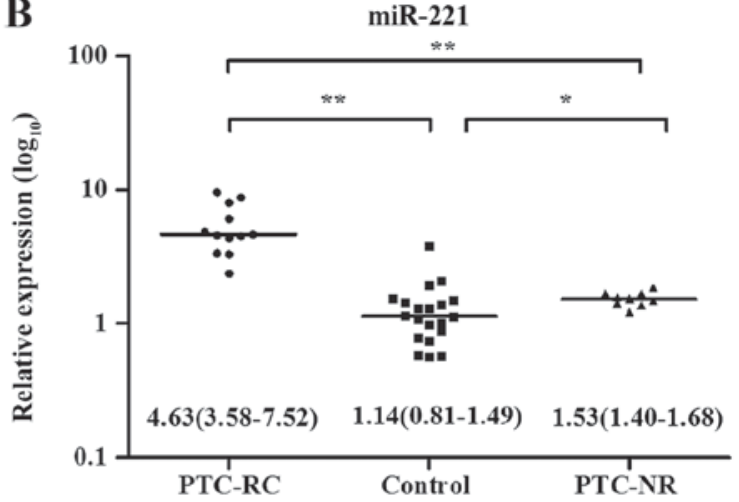

C

miR-146b

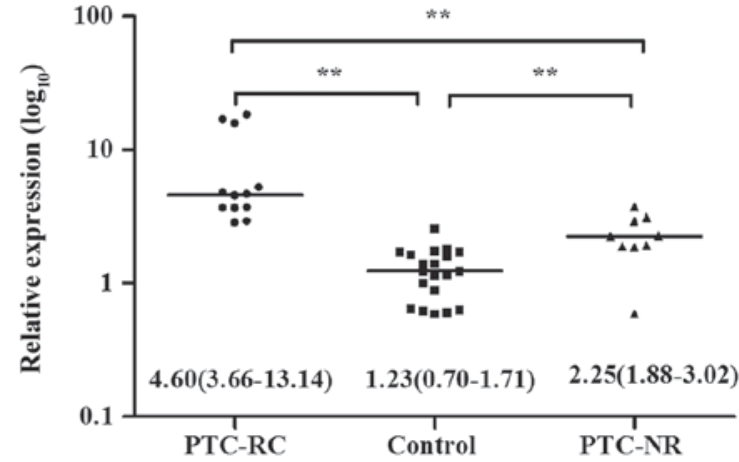

Figure 7. The relative expression levels of (A) miR-222, (B) miR-221 and (C) miR-146b in the PTC-RC group ( $\mathrm{n}=12$; median=7.53,4.63 and 4.60; range=3.38-9.53, 3.58-7.52 and 3.66-13.14, respectively) were significantly increased compared with the control $(\mathrm{n}=20 ;$ median=1.09, 1.14 and $1.23 ;$ range $=0.80-1.20,0.81-1.49$ and 0.70-1.71, respectively; ${ }^{\mathrm{P}}<0.05$ and $\left.{ }^{* *} \mathrm{P}<0.01\right)$ and $\mathrm{PTC}-\mathrm{NR}$ groups $(\mathrm{n}=9$; median=1.16, 1.53 and 2.25 ; range $=0.96-1.53$, 1.40-1.68 and 1.88-3.02, respectively; ${ }^{* *} \mathrm{P}<0.01$ ). miR, microRNA; PTC-RC, papillary thyroid carcinoma with recurrence; PTC-NR, papillary thyroid carcinoma without recurrence.

elevated in the PTC-NR group of patients compared with controls ( $\mathrm{P}=0.022$ and $\mathrm{P}=0.002$, respectively; Fig. 7).

\section{Discussion}

Since miRNAs were first identified in Caenorhabditis elegans in 1993 by Lee et al (46). To date, >1,000 human miRNAs have been reported in the miRBase sequence database (47). The majority of previous studies have examined miRNA expression in tumor cells and tissues from patients with PTC $(32,48-51)$. Although tissue miRNA profiles are useful for distinguishing BTN from PTC, obtaining tissue requires an invasive procedure, and these profiles are not able to be used as biomarkers for presurgical diagnoses. By contrast, serum sampling is minimally invasive and easy to perform, making it attractive when exploring potential biomarkers. There are several advantages to measuring levels of circulating miRNAs. Firstly, as nucleotide non-coding RNA, miRNA can be amplified and detected with high sensitivity and specificity in serum, plasma and other bodily fluids. Secondly, miRNA arrays and RT-qPCR methodologies allow the quantification of numerous miRNAs in a single experiment. The combined analysis of miRNAs and their co-expression patterns (miRNA networks) may enhance their predictive power. miRNAs are also relatively stable over time in the human blood and appear to be protected from degradation through various mechanisms (44). The stability of miRNA in bodily fluids and the numerous changes in expression in cancer suggest that circulating miRNAs may possess a diagnostic value. Previous studies have measured circulating miRNAs in serum and plasma as noninvasive biomarkers for cancer, including lung, breast and colorectal cancer (52-56).

To date, a limited number of studies have addressed the use of circulating miRNA quantification in patients with PTC. Yu et al (33) first reported that miR-222, miR-151-5p and let-7e were significantly overexpressed in patients with PTC compared with either patients with benign nodule or controls (33). Expression of these miRNAs correlated with certain clinicopathological variables, including nodal status, tumor size, multifocal lesion status and TNM stage, and the expression levels decreased significantly following tumor excision in patients with PTC (33). Another study performed in Australia identified serum expression levels of miR-222, miR-221 and miR-146b that were much higher in patients with PTC compared with in healthy controls and decreased significantly in postoperative patients with PTC compared with the preoperative levels (29). The same study also revealed that the plasma levels of miR-222, miR-221 and miR-146b were significantly overexpressed in preoperative patients with multinodular goiters compared with healthy controls. However, no significant difference was observed between the PTC and multinodular goiter groups prior to surgery (29). In addition, the study also demonstrated that miR-222 and miR-146b were overexpressed in tumor tissue samples of patients with PTC-RC compared with patients with PTC-NC (29). However, the expression of miR-222 and miR-146b in serum was not detected (29). By contrast, Lee et al (35) reported that the expression levels of miR-222 and miR-221 in the PTC group were 
increased compared with those in the benign group; however, these differences were not significant. Cantara et al (34) also identified miR-190 and miR-95 as being overexpressed in the serum of patients with PTC compared with patients with BTN and controls.

Although these studies have offered promising evidence that identifying circulating miRNAs is useful and formed the basis for our study, there remains controversy and ambiguity in these findings. Firstly, the diagnostic value of miR-222 and miR-146b were determined in patients with PTC compared with patients with BTN and healthy controls. Secondly, it was unclear whether the group with benign nodules in these studies had solitary nodules, multinodular goiter, or solitary nodules and multinodular goiter. In addition, these studies did not determine whether the circulating miRNAs are able to distinguish between patients with and without recurrence. Finally, the dynamic expression patterns of circulating miRNA have not yet been clearly elucidated. Therefore, additional studies are required to more comprehensively determine whether the presence of circulating miRNAs is able to determine diagnosis, prognosis and recurrence.

Therefore, the present study analyzed miRNA expression in the serum from a cohort of patients with PTC, patients with BTN and controls and reported 4 significant observations. Firstly, it was revealed that miR-222, miR-221 and miR-146b in patients with PTC were overexpressed in serum compared with patients with BTN and control subjects, as detected using RT-qPCR. The diagnostic value of these three miRNAs was also investigated using an ROC curve analysis, and the present study demonstrated that these three miRNAs may represent promising biomarkers and serve as an accurate diagnostic tool for the preoperative diagnosis of PTC. Secondly, the present study also reported the association between the expression levels of the three miRNAs and various clinicopathological features of patients with PTC. The analysis indicated that all three elevated miRNAs were associated with lymph node metastasis, extrathyroid invasion, advanced TNM stage, bilateral thyroid lesions and high risk patients. In addition, miR-222 was significantly associated with tumor size $(>2 \mathrm{~cm})$, and miR-221 was significantly associated with multifocal lesions.

The present study dynamically monitored these miRNAs at 1, 3, 6 and 12 months following surgery and revealed that their expression levels decreased rapidly in serum following surgery in the PTC group. Additionally, the expression levels of miR-222, miR-221 and miR-146b gradually decreased between 3 and 6 months following surgery in the PTC group. A similar pattern was observed with miR-146b expression in the BTN group prior to and subsequent to surgery. However, the miR-222 and miR-221 levels were stable and did not change significantly following surgery in the BTN group. The miR-146b level increased at 1 month following surgery compared with 3 months subsequent to surgery. The present study also confirmed that the miR-222, miR-221 and miR-146b expression levels in patients with PTC-RC were significantly increased compared with patients with PTC-NR or controls.

Several studies have reported the function and mechanism of upregulated miR-146b in PTC. Yip et al (57) and Wang et al (30) demonstrated that miR-146b and miR-222 are significantly overexpressed in aggressive PTC compared with nonaggressive PTC. Among BRAF-positive tumors, overexpression of miR-146b is associated with aggressive behavior, suggesting that it may additionally refine the prognostic significance of BRAF $(58,59)$. Previous studies have revealed that the overexpression of miR-146b was associated with PTC carcinogenesis and was associated with extrathyroidal invasion, advanced stages, BRAF mutations, large tumor sizes $(>2 \mathrm{~cm})$ and lower overall survival rates in patients with PTC $(38,57-59)$. These results highlight the importance of miR-146b in determining the aggression of PTC and may aid the identification of potential gene targets associated with tumor aggression in PTC. The present study demonstrated that serum miR-146b expression levels possess a poor prognostic value when dynamically monitoring patients with PTC. The target genes regulated by miR-146b remain largely unknown, and little has been reported regarding the molecular mechanisms by which miR-146b influences tumor aggression in PTC. Previously, Geraldo et al (60) demonstrated that miR-146b regulates the signal transduction pathways of transforming growth factor- $\beta$ (TGF- $\beta$ ) by repressing SMAD4 in thyroid tumorigenesis. miR-146b overexpression in PCCL3 cells also significantly increases cellular proliferation in the absence of TSH and confers resistance to TGF- $\beta$-mediated cell cycle arrest (61).

Previous studies have indicated that the miR-222 and miR-221 expression levels in the tumor tissues of patients with PTC are significantly increased compared with in patients with BTN and controls, and are closely associated with lymph node metastasis, advanced TNM stage and extrathyroidal invasion in patients with PTC $(51,62-65)$. Similar to previous studies, analysis in the present study indicated that elevated serum miR-222 and miR-221 levels are associated with lymph node metastasis, extrathyroidal invasion, advanced TNM stage and high risk in PTC patients. The present study initially identified that the overexpression of serum miR-222 is clearly associated with tumor size $(>2 \mathrm{~cm}$ ), and the overexpression of serum miR-221 is associated with bilateral tumor location in patients with PTC. As the two miRNAs are clustered on the X chromosome, they may be encoded by a single polycistronas previously suggested $(66,67)$. Previous studies $(68-71)$ have indicated that the target genes of miR-222 and miR-221 are p27, p57 and PUMA, and that these may perform essential roles in thyroid oncogenesis (72).

The dynamic expression patterns of circulating miRNAs have not yet been clearly and systematically reported for various cancer types, including PTC. Lee et al (29) identified that the plasma levels of miR-222, miR-221 and miR-146b decreased significantly in patients subsequent to a total thyroidectomy with central lymph node dissection between 2 and 6 weeks following surgery. To the best of our knowledge, the present study is the first to dynamically monitor 3 serum miRNAs at 1 year following surgery in patients with PTC. To additionally investigate whether the levels of these 3 miRNAs may be used to monitor postoperative progression, 3 miRNAs were used to perform the subsequent validation at different postoperative time points, including 1, 3, 6 and 12 months, in patients with PTC or BTN. The 3 miRNAs exhibited different expression levels in postoperative patients with PTC 12 months following surgery, and the expression levels steadily decreased at 1, 3, 6 and 12 months following surgery. It is speculated that these serum miRNAs are released into the peripheral blood from 
thyroid tissues and that they correlate closely with the development of PTC.

At present, no conclusive evidence has identified patients who are at higher risk of recurrence. Due to the alterations of these miRNA levels following thyroidectomy, studies with larger numbers of patients are required to confirm whether these miRNAs can serve as biomarkers for monitoring tumor recurrence and predicting prognosis. Lee et al (29) identified miR-222 and miR-146b as molecular markers of recurrence in tumor tissues; however, they did not measure serum expression in patients with PTC with recurrence. The present study is the first to compare these miRNAs in serum between patients with PTC with and without recurrence with either newly emerged lymph nodules or suspicious new neck masses following an initial thyroidectomy due to PTC. Recurrence was confirmed by pathology. The present results indicate that serum miR-222, miR-221 and miR-146b increased significantly in patients with recurrence compared with patients without recurrence and control subjects.

Serum miRNA levels may be tested periodically to monitor patients with suspected PTC or recurrence, preferably at clinically asymmetric stages. Based on the present results, a screening test for the expression of miRNA in serum would have a number of advantages. Firstly, since the test would be performed on a large population, it should be minimally invasive or noninvasive. Secondly, the presence, stability and reliable detectability of miRNA in serum make this sample easily obtained by minimally invasive methods. In addition, the screen is a cost-efficient test that can be performed using RT-qPCR. Finally, the expression levels of serum miRNA are specific and sensitive for PTC and are a potential tool for long-term surveillance. Therefore, this screen may be particularly useful in patients for whom the measurement of serum TG is not suitable, including patients with anti-TG antibodies or whose tumors have lost TG expression.

Several limitations of the present study must be noted. Firstly, this study is a randomized multicenter controlled trial with a selection bias for patients with PTC and BTN. Secondly, the miRNAs identified in the present study differed from those reported in other studies. It is speculated that this difference may be due to different genetic backgrounds and clinicopathological features of patients with PTC and BTN. Thirdly, the relatively small sample size and short-term follow-up resulted in insufficient information regarding prognosis and recurrence. Additional investigations with a larger cohort of samples and long-term follow-up are required to validate the observations of the present study.

In conclusion, the present study demonstrated that miR-222, miR-221 and miR-146b were overexpressed in patients with PTC compared with patients with BTN and controls, and their expression was associated with certain poorer prognostic variables. The present results also indicated that miR-222, miR-221 and miR-146b may serve as indexes for dynamic monitoring in patients with PTC, and these miRNAs are associated with PTC-RC. Therefore, miR-222, miR-221 and miR-146b have the potential to be novel non-invasive and effective diagnostic, prognostic and recurrent biomarkers for patients with PTC prior to and subsequent to surgery.

\section{Acknowledgements}

The present study was supported by grants from the Natural Science foundation of China (grant nos 81473053 and 81673108) and the National Basic Research Program of China (973 Program; grant no SQ2013CB051164).

\section{References}

1. Bann DV, Goyal N, Camacho F and Goldenberg D: Increasing incidence of thyroid cancer in the Commonwealth of Pennsylvania. JAMA Otolaryngol Head Neck Surg 140: 1149-1156, 2014.

2. N Howlader AMN and M Krapcho JG: SEER Cancer Statistics Review, 1975-2011. Bethesda, MD, National Cancer Institute, 2014.

3. Leenhardt L, Grosclaude P and Chérié-Challine L; Thyroid Cancer Committee: Increased incidence of thyroid carcinoma in France: A true epidemic or thyroid nodule management effects? Report from the French Thyroid Cancer Committee. Thyroid 14: 1056-1060, 2004.

4. Pacini F, Schlumberger M, Dralle H, Elisei R, Smit JW and Wiersinga W; European Thyroid Cancer: European consensus for the management of patients with differentiated thyroid carcinoma of the follicular epithelium. Eur J Endocrinol 154: 787-803, 2006.

5. American Thyroid Association (ATA) Guidelines Taskforce on Thyroid Nodules and Differentiated Thyroid Cancer, Cooper DS, Doherty GM, Haugen BR, Kloos RT, Lee SL, Mandel SJ, Mazzaferri EL, McIver B, Pacini F, et al: Revised American thyroid association management guidelines for patients with thyroid nodules and differentiated thyroid cancer. Thyroid 19: 1167-1214, 2009.

6. Cooper DS, Doherty GM, Haugen BR, Kloos RT, Lee SL, Mandel SJ, Mazzaferri EL, McIver B, Sherman SI and Tuttle RM; American Thyroid Association Guidelines Taskforce: Management guidelines for patients with thyroid nodules and differentiated thyroid cancer. Thyroid 16: 109-142, 2006.

7. Pusztaszeri MP, Bongiovanni M and Faquin WC: Update on the cytologic and molecular features of medullary thyroid carcinoma. Adv Anat Pathol 21: 26-35, 2014.

8. Zhao L, Gong Y, Wang J, Dawlett M, Huo L, Caraway NP and Guo M: Ultrasound-guided fine-needle aspiration biopsy of thyroid bed lesions from patients with thyroidectomy for thyroid carcinomas. Cancer Cytopathol 121: 101-107, 2013.

9. Lew JI, Snyder RA, Sanchez YM and Solorzano CC: Fine needle aspiration of the thyroid: Correlation with final histopathology in a surgical series of 797 patients. J Am Coll Surg 213: 188-195, 2011.

10. Cibas ES and Ali SZ: The bethesda system for reporting thyroid cytopathology. Thyroid 19: 1159-1165, 2009.

11. Gharib H, Papini E, Paschke R, Duick DS, Valcavi R, Hegedüs L and Vitti P; AACE/AME/ETA Task Force on Thyroid Nodules: American Association of Clinical Endocrinologists, Associazione Medici Endocrinologi and European Thyroid Association Medical guidelines for clinical practice for the diagnosis and management of thyroid nodules: Executive summary of recommendations. Endocr Pract 16: 468-475, 2010.

12. Leboulleux S, Rubino C, Baudin E, Caillou B, Hartl DM, Bidart JM, Travagli JP and Schlumberger M: Prognostic factors for persistent or recurrent disease of papillary thyroid carcinoma with neck lymph node metastases and/or tumor extension beyond the thyroid capsule at initial diagnosis. J Clin Endocrinol Metab 90: 5723-5729, 2005.

13. Suh YJ, Kwon H, Kim SJ, Choi JY, Lee KE, Park YJ, Park do J and Youn YK: Factors affecting the locoregional recurrence of conventional papillary thyroid carcinoma after surgery: A retrospective analysis of 3381 patients. Ann Surg Oncol 22: 3543-3549, 2015.

14. Spencer CA: Challenges of serum thyroglobulin (Tg) measurement in the presence of Tg autoantibodies. J Clin Endocrinol Metab 89: 3702-3704, 2004.

15. Woodmansee WW and Haugen BR: Uses for recombinant human TSH in patients with thyroid cancer and nodular goiter. Clin Endocrinol (Oxf) 61: 163-173, 2004.

16. Castagna MG, Brilli L, Pilli T, Montanaro A, Cipri C, Fioravanti C, Sestini F, Capezzone M and Pacini F: Limited value of repeat recombinant human thyrotropin (rhTSH)-stimulated thyroglobulin testing in differentiated thyroid carcinoma patients with previous negative rhTSH-stimulated thyroglobulin and undetectable basal serum thyroglobulin levels. J Clin Endocrinol Metab 93: 76-81, 2008. 
17. Snozek CL, Chambers EP, Reading CC, Sebo TJ, Sistrunk JW, Singh RJ and Grebe SK: Serum thyroglobulin, high-resolution ultrasound and lymph node thyroglobulin in diagnosis of differentiated thyroid carcinoma nodal metastases. J Clin Endocrinol Metab 92: 4278-4281, 2007.

18. Orlov S, Salari F, Kashat L, Freeman JL, Vescan A, Witterick IJ and Walfish PG: Post-operative stimulated thyroglobulin and neck ultrasound as personalized criteria for risk stratification and radioactive iodine selection in low- and intermediate-risk papillary thyroid cancer. Endocrine 50: 130-137, 2015.

19. Londero SC, Krogdahl A, Bastholt L, Overgaard J, Pedersen HB, Hahn CH, Bentzen J, Schytte S, Christiansen P, Gerke O, et al: Papillary thyroid carcinoma in Denmark, 1996-2008: Outcome and evaluation of established prognostic scoring systems in a prospective national cohort. Thyroid 25: 78-84, 2015.

20. Lu J, Getz G, Miska EA, Alvarez-Saavedra E, Lamb J, Peck D, Sweet-Cordero A, Ebert BL, Mak RH, Ferrando AA, et al: MicroRNA expression profiles classify human cancers Nature 435: 834-838, 2005

21. Volinia S, Calin GA, Liu CG, Ambs S, Cimmino A, Petrocca F Visone R, Iorio M, Roldo C, Ferracin M, et al: A microRNA expression signature of human solid tumors defines cancer gene targets. Proc Natl Acad Sci USA 103: 2257-2261, 2006.

22. Lawrie CH, Gal S, Dunlop HM, Pushkaran B, Liggins AP, Pulford K, Banham AH, Pezzella F, Boultwood J, Wainscoat JS, et al: Detection of elevated levels of tumour-associated microRNAs in serum of patients with diffuse large B-cell lymphoma. Br J Haematol 141: 672-675, 2008.

23. Kou CH, Zhou T, Han XL, Zhuang HJ and Qian HX Downregulation of mir-23b in plasma is associated with poor prognosis in patients with colorectal cancer. Oncol Lett 12: 4838-4844, 2016.

24. Hanke M, Hoefig K, Merz H, Feller AC, Kausch I, Jocham D, Warnecke JM and Sczakiel G: A robust methodology to study urine microRNA as tumor marker: microRNA-126 and microRNA-182 are related to urinary bladder cancer. Urol Oncol 28: 655-661, 2010.

25. Park NJ, Zhou H, Elashoff D, Henson BS, Kastratovic DA, Abemayor E and Wong DT: Salivary microRNA: Discovery, characterization, and clinical utility for oral cancer detection. Clin Cancer Res 15: 5473-5477, 2009.

26. Faam B, Ghaffari MA, Ghadiri A and Azizi F: Epigenetic modifications in human thyroid cancer. Biomed Rep 3: 3-8, 2015.

27. Yang Z, Yuan Z, Fan Y, Deng X and Zheng Q: Integrated analyses of microRNA and mRNA expression profiles in aggressive papillary thyroid carcinoma. Mol Med Rep 8: 1353-1358, 2013.

28. Peng Y, Li C, Luo DC, Ding JW, Zhang W and Pan G: Expression profile and clinical significance of microRNAs in papillary thyroid carcinoma. Molecules 19: 11586-11599, 2014.

29. Lee JC, Zhao JT, Clifton-Bligh RJ, Gill A, Gundara JS, Ip JC, Glover A, Sywak MS, Delbridge LW, Robinson BG and Sidhu SB: MicroRNA-222 and microRNA-146b are tissue and circulating biomarkers of recurrent papillary thyroid cancer. Cancer 119 : 4358-4365, 2013.

30. Wang Z, Zhang H, He L, Dong W, Li J, Shan Z and Teng W: Association between the expression of four upregulated miRNAs and extrathyroidal invasion in papillary thyroid carcinoma. Onco Targets Ther 6: 281-287, 2013.

31. Dettmer M, Perren A, Moch H, Komminoth P, Nikiforov YE and Nikiforova MN: Comprehensive MicroRNA expression profiling identifies novel markers in follicular variant of papillary thyroid carcinoma. Thyroid 23: 1383-1389, 2013.

32. He H, Jazdzewski K, Li W, Liyanarachchi S, Nagy R, Volinia S, Calin GA, Liu CG, Franssila K, Suster S, et al: The role of microRNA genes in papillary thyroid carcinoma. Proc Natl Acad Sci USA 102: 19075-19080, 2005.

33. Yu S, Liu Y, Wang J, Guo Z, Zhang Q, Yu F, Zhang Y, Huang K, $\mathrm{Li}$ Y, Song E, et al: Circulating microRNA profiles as potentia biomarkers for diagnosis of papillary thyroid carcinoma. J Clin Endocrinol Metab 97: 2084-2092, 2012.

34. Cantara S, Pilli T, Sebastiani G, Cevenini G, Busonero G, Cardinale S, Dotta F and Pacini F: Circulating miRNA95 and miRNA190 are sensitive markers for the differential diagnosis of thyroid nodules in a Caucasian population. J Clin Endocrinol Metab 99: 4190-4198, 2014.

35. Lee YS, Lim YS, Lee JC, Wang SG, Park HY, Kim SY and Lee BJ: Differential expression levels of plasma-derived miR-146b and miR-155 in papillary thyroid cancer. Oral Oncol 51: 77-83, 2015 .
36. Vrachimis A, Gerss J, Stoyke M, Wittekind C, Maier T, Wenning C, Rahbar K, Schober O and Riemann B: No significant difference in the prognostic value of the 5th and 7th editions of AJCC staging for differentiated thyroid cancer. Clin Endocrinol (Oxf) 80: 911-917, 2014

37. Cady B and Rossi R: An expanded view of risk-group definition in differentiated thyroid carcinoma. Surgery 104: 947-953, 1988.

38. Sun Y, Yu S, Liu Y, Wang F, Liu Y and Xiao H: Expression of miRNAs in papillary thyroid carcinomas is associated with BRAF mutation and clinicopathological features in Chinese patients. Int J Endocrinol 2013: 128735, 2013.

39. Chou CK, Chen RF, Chou FF, Chang HW, Chen YJ, Lee YF, Yang KD, Cheng JT, Huang CC and Liu RT: miR-146b is highly expressed in adult papillary thyroid carcinomas with high risk features including extrathyroidal invasion and the BRAF (V600E) mutation. Thyroid 20: 489-494, 2010.

40. Kroh EM, Parkin RK, Mitchell PS and Tewari M: Analysis of circulating microRNA biomarkers in plasma and serum using quantitative reverse transcription-PCR (qRT-PCR). Methods 50: 298-301, 2010

41. Toiyama Y, Tanaka K, Inoue Y, Mohri Y and Kusunoki M: Circulating cell-free microRNAs as biomarkers for colorectal cancer. Surg Today 46: 13-24, 2016.

42. Xiang M, Zeng Y, Yang R, Xu H, Chen Z, Zhong J, Xie H, Xu Y and Zeng X: U6 is not a suitable endogenous control for the quantification of circulating microRNAs. Biochem Biophys Res Commun 454: 210-214, 2014.

43. McDermott AM, Kerin MJ and Miller N: Identification and validation of miRNAs as endogenous controls for RQ-PCR in blood specimens for breast cancer studies. PLoS One 8: e83718, 2013.

44. Alegre E, Sanmamed MF, Rodriguez C, Carranza O, Martin-Algarra S and Gonzalez A: Study of circulating microRNA-125b levels in serum exosomes in advanced melanoma. Arch Pathol Lab Med 138: 828-832, 2014.

45. Livak KJ and Schmittgen TD: Analysis of relative gene expression data using real-time quantitative PCR and the 2(-Delta Delta $\mathrm{C}(\mathrm{T}))$ method. Methods 25: 402-408, 2001

46. Lee RC, Feinbaum RL and Ambros V: The C. elegans heterochronic gene lin-4 encodes small RNAs with antisense complementarity to lin-14. Cell 75: 843-854, 1993.

47. Griffiths-Jones S, Saini HK, van Dongen S and Enright AJ: miRBase: Tools for microRNA genomics. Nucleic Acids Res 36 (Database issue): D154-D158, 2008

48. Wang C, Lu S, Jiang J, Jia X, Dong X and Bu P: Hsa-microRNA101 suppresses migration and invasion by targeting Rac1 in thyroid cancer cells. Oncol Lett 8: 1815-1821, 2014.

49. Nikiforova MN, Tseng GC, Steward D, Diorio D and Nikiforov YE: MicroRNA expression profiling of thyroid tumors: Biological significance and diagnostic utility. J Clin Endocrinol Metab 93: 1600-1608, 2008.

50. Zhu YZ, Zheng K, Zhang $\mathrm{HH}$, Chen L, Wu KL, Ren $\mathrm{CH}$, Wang ZC, Kong LJ, Ruan WH and Chen XJ: Expression of microRNA-155 in papillary thyroid carcinoma and its clinical significance. Nan Fang Yi Ke Da Xue Xue Bao 36: 1364-1368, 2016 (In Chinese).

51. Xu J, Zhang D, Niu Q, Nan Y, Shi C, Zhao H and Liang X: Value of distinguishing differentiated thyroid carcinoma by miRNA. Oncol Lett 12: 79-82, 2016.

52. Engelhardt S: Small RNA biomarkers come of age. J Am Coll Cardiol 60: 300-303, 2012.

53. Markou A, Sourvinou I, Vorkas PA, Yousef GM and Lianidou E: Clinical evaluation of microRNA expression profiling in non small cell lung cancer. Lung Cancer 81: 388-396, 2013.

54. Eichelser C, Flesch-Janys D, Chang-Claude J, Pantel K and Schwarzenbach H: Deregulated serum concentrations of circulating cell-free microRNAs miR-17, miR-34a, miR-155, and miR-373 in human breast cancer development and progression. Clin Chem 59: 1489-1496, 2013.

55. Menendez P, Villarejo P, Padilla D, Menéndez JM and Montes JA: Diagnostic and prognostic significance of serum microRNAs in colorectal cancer. J Surg Oncol 107: 217-220, 2013.

56. Ng EK, Chong WW, Jin H, Lam EK, Shin VY, Yu J, Poon TC, Ng SS and Sung JJ: Differential expression of microRNAs in plasma of patients with colorectal cancer: A potential marker for colorectal cancer screening. Gut 58: 1375-1381, 2009.

57. Yip L, Kelly L, Shuai Y, Armstrong MJ, Nikiforov YE, Carty SE and Nikiforova MN: MicroRNA signature distinguishes the degree of aggressiveness of papillary thyroid carcinoma. Ann Surg Oncol 18: 2035-2041, 2011. 
58. Chou CK, Yang KD, Chou FF, Huang CC, Lan YW, Lee YF, Kang HY and Liu RT: Prognostic implications of miR-146b expression and its functional role in papillary thyroid carcinoma. J Clin Endocrinol Metab 98: E196-E205, 2013.

59. Sun M, Fang S, Li W, Li C, Wang L, Wang F and Wang Y: Associations of miR-146a and miR-146b expression and clinical characteristics in papillary thyroid carcinoma. Cancer Biomark 15: 33-40, 2015.

60. Geraldo MV, Yamashita AS and Kimura ET: MicroRNA miR-146b-5p regulates signal transduction of TGF- $\beta$ by repressing SMAD4 in thyroid cancer. Oncogene 31: 1910-1922, 2012.

61. Lima CR, Geraldo MV, Fuziwara CS, Kimura ET and Santos MF: MiRNA-146b-5p upregulates migration and invasion of different papillary thyroid carcinoma cells. BMC Cancer 16: 108, 2016.

62. Cong D, He M, Chen S, Liu X, Liu X and Sun H: Expression profiles of pivotal microRNAs and targets in thyroid papillary carcinoma: an analysis of The Cancer Genome Atlas. Onco Targets Ther 8: 2271-2277, 2015.

63. Lee JC, Zhao JT, Gundara J, Serpell J, Bach LA and Sidhu S: Papillary thyroid cancer-derived exosomes contain miRNA-146b and miRNA-222. J Surg Res 196: 39-48, 2015.

64. Chen YT, Kitabayashi N, Zhou XK, Fahey TJ III and Scognamiglio T: MicroRNA analysis as a potential diagnostic tool for papillary thyroid carcinoma. Mod Pathol 21: 1139-1146, 2008.

65. Diao Y, Fu H and Wang Q: MiR-221 exacerbate cell proliferation and invasion by targeting TIMP3 in papillary thyroid carcinoma. Am J Ther: Apr 12, 2016 (Epub ahead of print).
66. Zhang L, Wang T, Wright AF, Suri M, Schwartz CE, Stevenson RE and Valle D: A microdeletion in Xp11.3 accounts for co-segregation of retinitis pigmentosa and mental retardation in a large kindred. Am J Med Genet A 140: 349-357, 2006.

67. Yang QE, Racicot KE, Kaucher AV, Oatley MJ and Oatley JM: MicroRNAs 221 and 222 regulate the undifferentiated state in mammalian male germ cells. Development 140: 280-290, 2013.

68. Martins CS, Camargo RC, Saggioro FP, Neder L, Machado HR, Moreira AC and de Castro M: P27/CDKN1B translational regulators in pituitary tumorigenesis. Horm Metab Res 48: 840-846, 2016.

69. Castagnino P, Kothapalli D, Hawthorne EA, Liu SL, Xu T, Rao S, Yung Y and Assoian RK: miR-221/222 compensates for Skp2-mediated p27 degradation and is a primary target of cell cycle regulation by prostacyclin and cAMP. PLoS One 8: e56140, 2013.

70. Kothapalli D, Castagnino P, Rader DJ, Phillips MC, Lund-Katz S and Assoian RK: Apolipoprotein E-mediated cell cycle arrest linked to p27 and the Cox2-dependent repression of miR221/222. Atherosclerosis 227: 65-71, 2013

71. Sun K, Wang W, Lei ST, Wu CT and Li GX: MicroRNA-221 promotes colon carcinoma cell proliferation in vitro by inhibiting CDKN1C/p57 expression. Nan Fang Yi Ke Da Xue Xue Bao 31: 1885-1889, 2011 (In Chinese).

72. Visone R, Russo L, Pallante P, De Martino I, Ferraro A, Leone V, Borbone E, Petrocca F, Alder H, Croce CM and Fusco A: MicroRNAs (miR)-221 and miR-222, both overexpressed in human thyroid papillary carcinomas, regulate p27Kip1 protein levels and cell cycle. Endocr Relat Cancer 14: 791-798, 2007. 